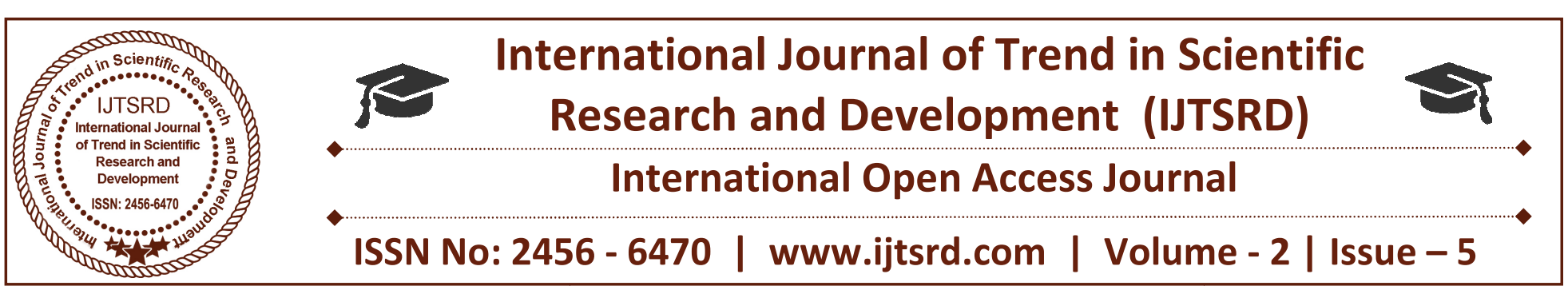

\title{
Biosorption of Copper (II) Ions by Eclipta Alba Leaf Powder from Aqueous Solutions
}

\author{
B. Kavitha, R. Arunadevi \\ Assistant Professor, PG \& Research Department of Chemistry, C.P.A. College, \\ Bodinayakanur, Tamil Nadu, India
}

\begin{abstract}
The removal of heavy metals from industrial wastewater is of great concern as heavy metals are non-biodegradable, toxic elements that cause serious health problems if disposed of in the surrounding environment. The present study, Karisalangkani (Eclipta Alba) leaves were used for the adsorption of heavy metals like copper ( $\mathrm{Cu}$ (II)) ions. The bio sorbent was characterized using SEM and BET analysis. The bio sorption experiments are conducted through batch system. The operating parameters studied were initial metal ion concentration, adsorbent dosage, initial solution $\mathrm{pH}$, contact time and effect of temperature Adsorption equilibrium is achieved in $30 \mathrm{~min}$ and the adsorption kinetics of $\mathrm{Cu}$ (II) is found to follow a pseudo-second-order kinetic model. Equilibrium data for $\mathrm{Cu}$ (II) adsorption are fitted well by Langmuir isotherm model. The maximum adsorption capacity for $\mathrm{Cu}$ (II) ions is estimated to be $9.2 \mathrm{mg} / \mathrm{g}$ at $25{ }^{\circ} \mathrm{C}$. The experimental result shows that the materials have good potential to remove heavy metals from effluent and good potential as an alternate low cost adsorbent. Due to their outstanding adsorption capacities, Eclipta Alba is excellent sorbents for the removal of copper (II) ions.
\end{abstract}

Keywords: Eclipta Alba, heavy metal, adsorption, pseudo first order kinetic.

\section{INTRODUCTION}

Industrial wastewater treatment for the removal of pollutants such as heavy metal ions remains a worldwide challenge. Heavy metal ions discharged with industrial effluents usually find their way into receiving water bodies such as rivers, lakes and streams increasing their pollution. Copper is one of the heavy metals most toxic to living organisms and

one of the most widespread heavy metals in the environment [1]. Although some trace metals are considered as essential plant nutrients. Most heavy metals are of considerable health and environmental concern because of their toxicity and bio accumulative behavior [2-4]. $\mathrm{Pb}^{2+}, \mathrm{Cu}^{2+}, \mathrm{Fe}^{3+}$ and $\mathrm{Cr}^{3+}$ are especially common metals that tend to accumulate in organisms, causing numerous diseases and disorders [5]. Copper is an essential trace element for human metabolism, however, it is toxic at concentrations above $2 \mathrm{mg} / \mathrm{L}$ [6]. Ingestion of large doses irritate the mucous membranes, damage the hair and can cause necrotic changes in the liver and kidneys [7]. Copper is present in wastewaters coming from energy industries (such as PILCAM in Cameroon), the production of certain pesticides and in the manufacture of contraceptives in medicine. Removal of metal ions from wastewater in an effective manner has become an important issue. Efficient methods for the removal of metals have resulted in the development of new separation techniques. Precipitation, ion-exchange, flocculation, adsorption, electro-chemical processes, electrodialysis, nano-filtration and reverse osmosis are commonly applied for the treatment of wastewater [8]. However, these methods are either inefficient or expensive when heavy metals exist in low concentrations [9]. Additionally, these methods may also affect the generation of secondary wastes, which are difficult to treat. Adsorption is an alternative technology in which increased amount of study has been focused because of cost effectiveness; local availability \& technical feasibility for the removal of heavy metal ions form the wastewater [10]. In recent years, bio sorption has been suggested as being cheaper and more effective than chemical or physical 
technologies. Low cost, high efficiency, minimization of chemical and biological sludge are the most important advantages of bio sorption technique. Moreover, bio sorbent regeneration and metal recovery is also possible. The mechanism of binding of metal ions by adsorbents may depend on the chemical nature of metal ions (species size and ionic charge), the type of biomass, environmental conditions ( $\mathrm{pH}$, temperature, ionic strength) and existence of competing organic or inorganic metal chelators. Natural materials that are available in large quantities or certain waste products from agricultural operation may have the potential as inexpensive sorbents.

The aim of the present study is to investigate the bio sorption of copper (II) on Eclipta Alba leaves powder. The effect of time, initial concentration of the metal, solution $\mathrm{pH}$ and adsorbent dosage on the bio sorption are also studied. The experimental data were fitted to Langmuir, Freundlich and Temkin equations, to determine which isotherm most closely correlates with experimental data. The first-order Lagergren, pseudo-second-order and second-order equations were adopted to test the experimental data.

\section{MATERIALS AND METHODS}

\subsection{Chemicals}

All the chemicals used were of analytical reagent grade. Copper nitrate trihydrate $\left(\mathrm{Cu}\left(\mathrm{NO}_{3}\right)_{2} \cdot 3 \mathrm{H}_{2} \mathrm{O}\right)$ was used for preparation of stock solutions. Hydrochloric acid and Sodium hydroxide were used to adjust the solution $\mathrm{pH}$. Distilled water was used throughout the experimental studies.

\subsection{Biosorbent collection and preparation}

The Eclipta Alba leaves (EA) were collected from Botanical garden present in C. P. A. College, Bodinayakanur. The EA were washed thoroughly with distilled water and boiled to remove colour and impurities. They were dried in a hot air oven at $105^{\circ} \mathrm{C}$ and ground to a uniform size of $0.8 \mathrm{~mm}$. So prepared EA particles were used for further studies

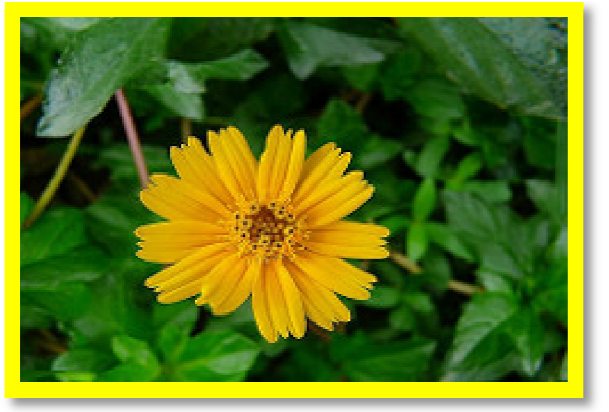

Fig.1. Eclipta Alba leaves

\subsection{Stock solution of metals}

A stock solution $(1000 \mathrm{mg} / \mathrm{l})$ of $\mathrm{Cu}$ (II) was prepared dissolving $3.802 \mathrm{~g}$ of copper nitrate trihydrate in $\mathrm{DD}$ water. Working solution was prepared by diluting stock solution with distilled water.

\subsection{Determination of Copper (II)}

The copper ion concentration in the liquid phase was determined spectrophotometrically by making a complex with sodium diethyl dithio carbamate.

$10 \mathrm{ml}$ of the $\mathrm{Cu}$ (II) solution was pipetted into a beaker, and to this $5 \mathrm{ml}$ of $25 \%$ aqueous citric acid solution was added. The $\mathrm{pH}$ was adjusted to $8.5 \mathrm{using}$ dilute ammonia. To this, $15 \mathrm{ml}$ of $4 \%$ EDTA was added and the solution cooled to room temperature. This was then transferred to a separating funnel, and $10 \mathrm{ml}$ of $0.2 \%$ aqueous sodium diethyl dithiocarbamate solution was added and shaken for 45 sec. A yellow brown colour developed in the solution. $20 \mathrm{ml}$ of Chloroform was pipetted into the funnel and shaken for 30 seconds. The organic layer acquired a yellow colour. This was shaken for $15 \mathrm{sec}$ and the phases were allowed to separate. The aqueous layer was removed. To the organic layer, $20 \mathrm{ml}$ of $5 \%$ $\mathrm{H}_{2} \mathrm{SO}_{4}(\mathrm{~V} / \mathrm{V})$ was added, shaken for $15 \mathrm{sec}$, and the organic phase was separated. The absorbance was measured at 435 nmagainst a blank.

\subsection{Characterization of bio sorbents}

The bio sorbent were characterized using a number of techniques including: Fourier transform infrared spectroscopy (FT-IR), scanning electron microscopy (SEM) and Brunauer-Emmet-Teller (BET) surface area analysis.

\subsection{Adsorption experiment}

Batch adsorption experiments of copper was carry out to determined the adsorption capacity of Eclipta Alba at different metal concentrations ranging from 10 to $80 \mathrm{mg} / \mathrm{L}$ and a fixed amount $(100 \mathrm{mg} / \mathrm{L})$ of Eclipta Alba in order to calculate the adsorption constant using different isotherms. $300 \mathrm{~mL}$ of different concentration of $\mathrm{Cu}$ (II) solutions ranging from 100$500 \mathrm{mg} / \mathrm{L}$ were used. The Eclipta Alba $(100 \mathrm{mg} / \mathrm{L})$ was added to flasks and agitated at $25{ }^{\circ} \mathrm{C}$ and 1000 rpm for $180 \mathrm{~min}$. The initial and final concentrations of the solutions were measured were determined by UV - Visible spectrophotometer at the maximum adsorption wavelength and the adsorption capacities of the adsorbent were calculated. After equilibrium was attained, the metal uptake capacity for each 
sample was calculated according to a mass balance on the metal ion using equation (1):

$$
q_{e}=\frac{\left(C_{0}-C_{e}\right) V}{m}
$$

Where $\mathrm{m}$ is the mass of adsorbent $(\mathrm{g}), \mathrm{V}$ is the volume of the solution $(\mathrm{L}), \mathrm{C}_{0}$ is the initial concentration of metal (mg $\left.\mathrm{L}^{-1}\right), \mathrm{C}_{\mathrm{e}}$ is the equilibrium metal concentration $\left(\mathrm{mg} \mathrm{L}^{-1}\right)$ and $\mathrm{q}_{\mathrm{e}}$ is the metal quantity adsorbed at equilibrium $(\mathrm{mg} / \mathrm{g})$. Experiments were carried out at different initial $\mathrm{pH}$ values. The initial $\mathrm{pH}$ of the solution was adjusted with either $\mathrm{HCl}$ or $\mathrm{NaOH}$. The percent removal of metals from the solution was calculated by the following equation (2).

$$
\text { \%removal }=\frac{C_{0}-C_{e}}{C_{0}} \times 100
$$

Where $\mathrm{C}_{0}(\mathrm{mg} / \mathrm{L})$ is the initial metal ion concentration and $\mathrm{C}_{\mathrm{e}}(\mathrm{mg} / \mathrm{L})$ is the final metal ion concentration in the solution.

\section{RESULTS AND DISCUSSION}

\subsection{SEM analysis}

The surface morphology studies of bio sorbent were showed octahedral rod shaped crystals as shown in Fig. 2.

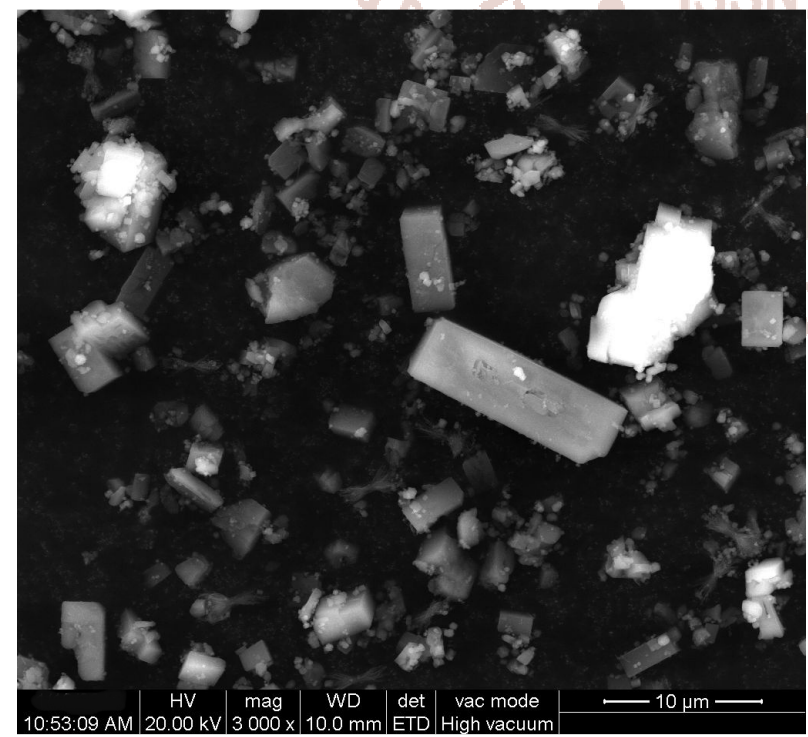

Fig.2. SEM image of EA

\subsection{BET surface area analysis}

The metal -bio sorption capacity, surface properties and active functional groups of any bio sorbents could be explored from surface area characterization.
Surface properties of EA were examined through BET. The surface properties of EA was measured shown in Fig. 3. These bio sorbents have noticeable micro pore and mesopore area with a magnitude of $21.17 \mathrm{~m}^{2} / \mathrm{g}$. All pores of EA are mesopore $(100 \%)$ and total pore volume was $0.03 \mathrm{~cm}^{3} / \mathrm{g}$. In addition, the mean micro pore and mesopore sizes of the EA's powder were found to be 8.71 and $40.18 \AA$, respectively, suggesting that this bio sorbent has fallen within the region of mesopore based on IUPAC-classification. The high pore area, pore volume and pore sizes indicated the numerous binding sites on the EA surfaces.

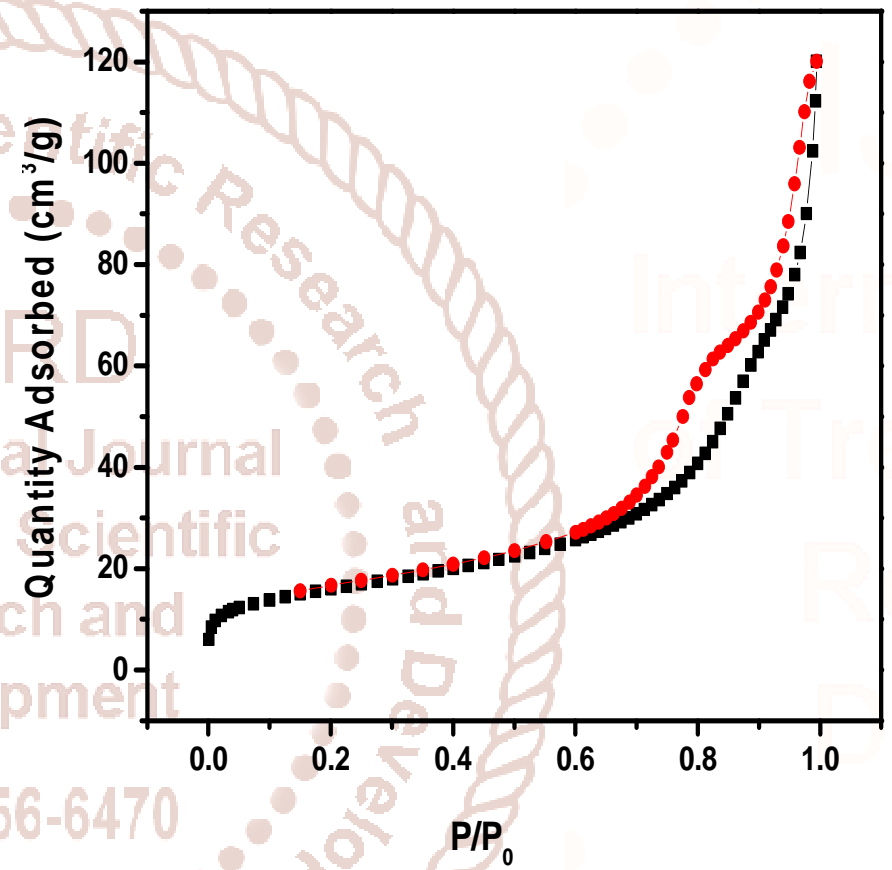

Fig.3. BET surface area of EA

\subsection{Effect of initial metal ion concentration}

The initial concentration of $\mathrm{Cu}$ (II) provides an important driving force to outweigh all mass transfer resistance of metal between the aqueous and solid phases. Removal of $\mathrm{Cu}$ (II) for various initial concentrations (10 to $80 \mathrm{mg} / \mathrm{L})$ by EA $(100 \mathrm{mg})$ at 180 min contact time and at $\mathrm{pH} 6$ has been depicted in the Fig. 4. The percentage $\mathrm{Cu}$ (II) adsorbed decreased $92 \%$ to $20 \%$ with increase in initial concentration from $10 \mathrm{mg} / \mathrm{L}$ to $80 \mathrm{mg} / \mathrm{L}$. More adsorption capacity at higher initial metal concentration may be due the presence of more metal ion at increasing initial metal concentration. It reflects that the resistance to mass transfer reduces therefore the removal percentage decreases at higher metal concentration [11]. Based on the experimental values, $10 \mathrm{mg} / \mathrm{L} \mathrm{Cu}$ (II) concentration is selected as the optimized value for further use. 
Table-1

\begin{tabular}{|c|c|}
\hline $\begin{array}{c}\text { Initial metal ion } \\
\text { concentration (mg/L) }\end{array}$ & $\%$ Removal \\
\hline 10 & 92 \\
\hline 20 & 84 \\
\hline 30 & 75 \\
\hline 40 & 67 \\
\hline 50 & 58 \\
\hline 60 & 49 \\
\hline 70 & 37 \\
\hline 80 & 20 \\
\hline
\end{tabular}

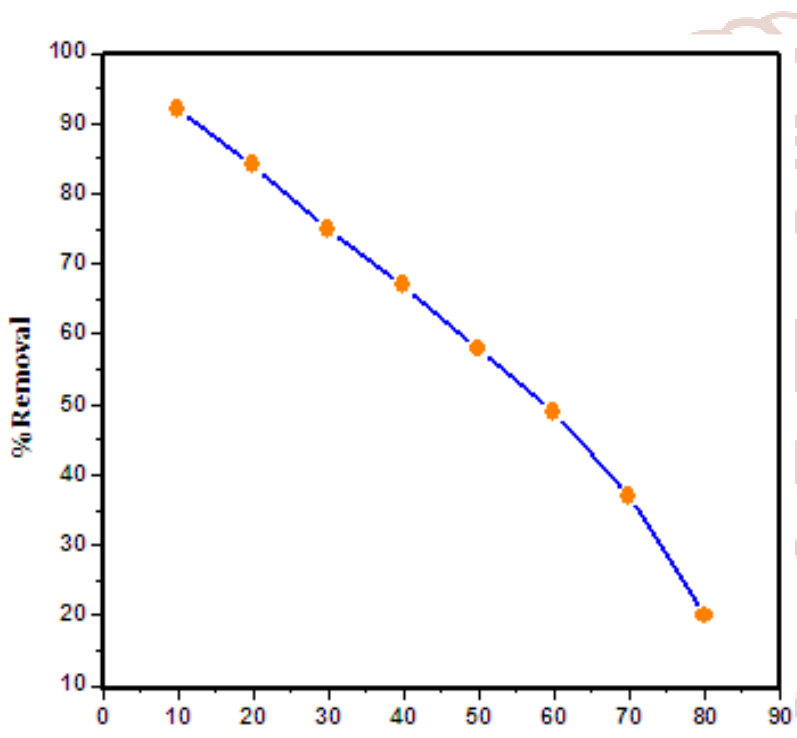

Fig.4. Effect of initial metal ion concentration (mg/L)
Table-2

\begin{tabular}{|c|c|}
\hline $\mathrm{pH}$ & $\%$ Removal \\
\hline 2 & 22 \\
\hline 3 & 45 \\
\hline 4 & 56 \\
\hline 5 & 78 \\
\hline 6 & 92 \\
\hline 7 & 75 \\
\hline 8 & 67 \\
\hline 9 & 61 \\
\hline
\end{tabular}

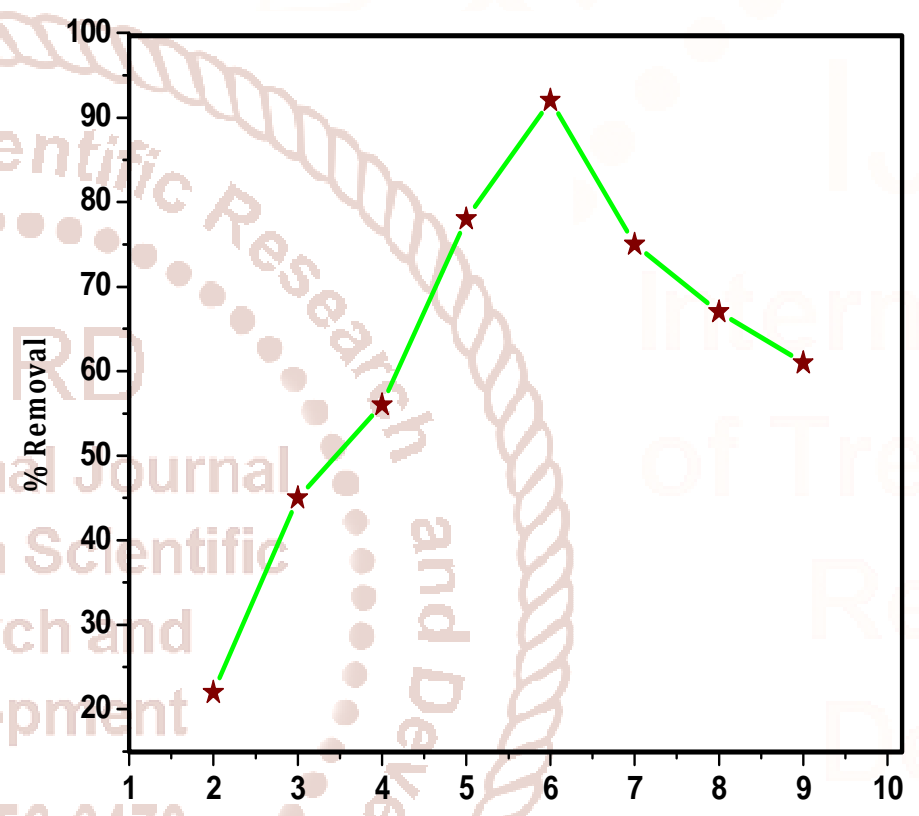

Fig.5. Effect of pH

\subsection{Effect of pH}

$\mathrm{pH}$ influences the surface charge of the adsorbent, the degree of ionization and the species of adsorb ate. So the $\mathrm{pH}$ of the aqueous solution is an important controlling parameter in the heavy metal adsorption process [12]. The effect of $\mathrm{pH}$ on the adsorption of $\mathrm{Cu}$ (II) by EA was shown in Fig. 5. The effect of solution $\mathrm{pH}$ on the adsorption of metal ions onto EA was evaluated in the $\mathrm{pH}$ range of 2 to 9 . The percentage removal of $\mathrm{Cu}$ (II) increased with an increase in $\mathrm{pH}$. The equilibrium adsorption capacity was observed at $\mathrm{pH} 6$ for $\mathrm{Cu}$ (II) ions. Therefore, at low $\mathrm{pH}$ values $(\mathrm{pH}<2.0)$ EA showed very low tendency for uptake of $\mathrm{Cu}$ (II) ions due to protonation of its functional groups or competition of $\mathrm{H}^{+}$with metal ions for binding sites. As the $\mathrm{pH}$ increased, there were fewer $\mathrm{H}^{+}$ions present in the solution and consequently more negatively charged sites were made available and this facilitated greater metal ions uptake by electrostatic attraction.

\subsection{Effect of contact time}

The impact of contact time on adsorption of $\mathrm{Cu}$ (II) can be seen from Fig.6. It is clearly depicted in the figure that the rate of adsorption is very high initially. But at later stages, the rate of adsorption decreases. The concentration of $\mathrm{Cu}$ (II) ions nearly remains constant after 180 minutes. It is chiefly because of the saturation of these active sites on the EA which do not permit furthermore adsorption to occur. This can be explained by the fact that initially, the quantity of sites on the surface is very large which allows adsorption to take place very easily. But with the passage of time, the active sites get saturated thereby reducing the rate at which adsorption occurs. As a result, the extent of copper removal decreased with increase in contact time, which is dependent on the number of vacant sites on the surface of resin. Based on these results 180 min was considered as the optimum time for the rest of the experiments $[13,14]$. 
Table-3

\begin{tabular}{|c|c|}
\hline Contact time (min) & \% Removal \\
\hline 0 & 20 \\
\hline 30 & 37 \\
\hline 60 & 49 \\
\hline 90 & 58 \\
\hline 120 & 67 \\
\hline 150 & 75 \\
\hline 180 & 92 \\
\hline
\end{tabular}

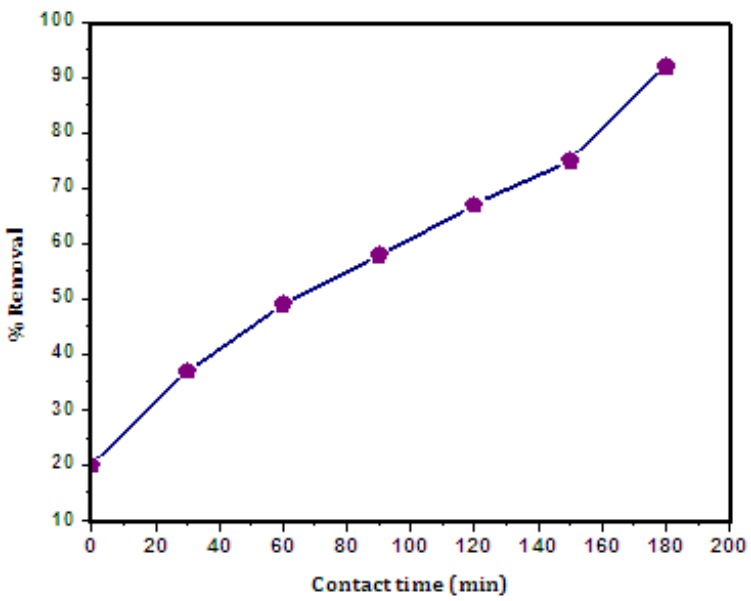

Fig.6. Effect of contact time ( $\mathrm{min}$ )

\subsection{Influence of initial adsorbent dosage}

The amount of adsorbent dosage was varied in the given rang e $100 \mathrm{mg} / \mathrm{L}$ to $500 \mathrm{mg} / \mathrm{L}$. It was observed from the graphs that increasing the dosage increases the $\%$ removal of $\mathrm{Cu}$ (II). It can be attributed to the increase in adsorbent sites for more adsorption of the $\mathrm{Cu}$ (II) at the fixed $10 \mathrm{mg} / \mathrm{L}$ [15].

\section{Table-4}

\begin{tabular}{|c|c|}
\hline Asorbent dose (mg/L) & \% Removal \\
\hline 100 & 22 \\
\hline 200 & 44 \\
\hline 300 & 58 \\
\hline 400 & 75 \\
\hline 500 & 92 \\
\hline
\end{tabular}

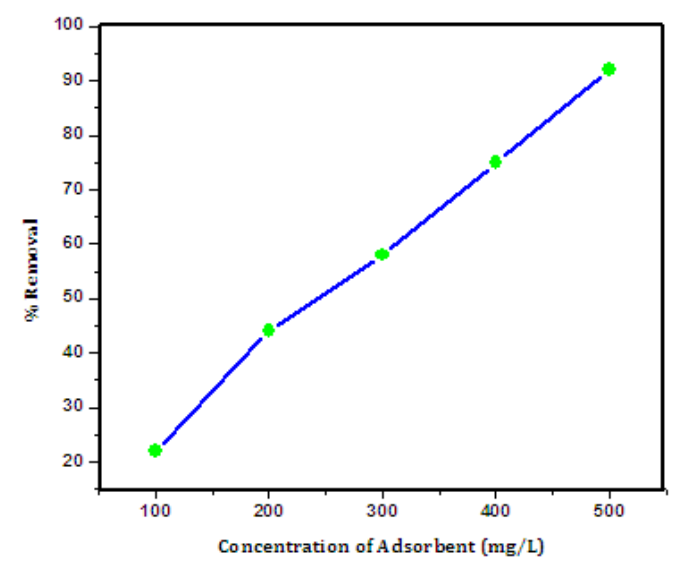

Fig.7. Effect of adsorbent concentration (mg/L)

\subsection{The study of adsorption isotherm models}

Among various plots employed for analyzing the nature of adsorb ate-adsorbent interaction, adsorption isotherm is the most significant. The results of adsorption studies of $\mathrm{Cu}$ (II) at different concentrations ranging from 10 to $80 \mathrm{mg} / \mathrm{L}$ on a fixed amount of adsorbent are expressed by three of the most popular isotherm theories viz., Freundlich, Langmuir and Temkin isotherms. These isotherm equations are as follows:

Langmuir

$\frac{C_{e}}{q_{e}}=\frac{1}{q_{o} b}+\frac{C_{e}}{q_{o}}$

Freundlich

$\log q_{e}=\log K_{f}+\frac{1}{n} \log C_{e}$

Temkin

$q_{e}=R T / b \ln K_{t}+R T / b \ln C_{e}$

Where $\mathrm{C}_{\mathrm{e}}\left(\mathrm{mg} \mathrm{L}^{-1}\right)$ is the equilibrium concentration of $\mathrm{Cu}$ (II) in solution, $\mathrm{q}_{\mathrm{e}}\left(\mathrm{mg} \mathrm{g} \mathrm{g}^{-1}\right)$ is the equilibrium adsorption capacity of EA, $\mathrm{q}_{0}\left(\mathrm{mg} \mathrm{g}^{-1}\right)$ is the maximum adsorption capacity of EA for monolayer coverage, $\mathrm{b}$ is related to the energy of adsorption $(\mathrm{L} / \mathrm{mg}), \mathrm{K}_{\mathrm{f}}$ and $\mathrm{n}$ are the Freundlich constants. $\mathrm{K}_{\mathrm{f}}$ is related to the adsorption equilibrium constant, $\mathrm{n}$ corresponds to the number of active sites in the adsorbent required for metal ions to adsorb. Where $b$ is the Temkin constant related to the heat of adsorption $\left(\mathrm{J} \mathrm{mol}^{-1}\right)$ and $\mathrm{K}_{\mathrm{t}}$ is the Temkin isotherm constant $\left(\mathrm{L} \mathrm{g}^{-1}\right)$. The slope and intercept of linear plots of $c_{e} / q_{e}$ versus $c_{e}$ yielded values of $1 / q_{0}$ and $1 /\left(b \cdot q_{0}\right)$ for Equation (3). The slope and intercept of linear plots of $\ln q_{e}$ versus $\ln c_{e}$ for Equation (4) produced values of $1 / \mathrm{n}$ and $\ln \mathrm{K}$.

In this part, the results and adsorption isotherm constants of the most common isotherms including Freundlich, Langmuir and Temkin have been illustrated in Table 5. Isotherm is assumed to be the most important parameter in designing adsorption systems and describes the relation between adsorbate concentration and adsorption capacity of an adsorbent. Regarding to Table 5 and values of linear regression coefficients. The amounts of $\mathrm{R}^{2}$ in Langmuir isotherm for $\mathrm{Cu}$ (II) adsorption by EA were higher than the amount of $\mathrm{R}^{2}$ for other isotherms. So it can be said with certainty that $\mathrm{Cu}$ (II) adsorption by EA follows this isotherm. Langmuir model estimated that the maximum amount of $\mathrm{Cu}$ (II) adsorption 
capacity $\left(\mathrm{q}_{\max }\right)$ by EA was $9.2 \mathrm{mg} / \mathrm{g} . \mathrm{K}_{\mathrm{L}}$ is a constant that increases when the size of adsorbent molecules increased [17]. If dimensionless parameter of $\mathrm{R}_{\mathrm{L}}=0$, the adsorption is irreversible and if $0<\mathrm{R}_{\mathrm{L}}<1$, the adsorption is Favorable and if $\mathrm{R}_{\mathrm{L}}=1$, the adsorption is linear and if $R_{L}>1$, then the adsorption is unfavorable. According to the results of the Langmuir isotherm for adsorption of $\mathrm{Cu}$ (II), the amounts $\mathrm{R}_{\mathrm{L}}$ for EA was between 0 and 1 , so $\mathrm{Cu}$ (II) adsorption by EA is Favorable [18].

\section{Table-5 the Isotherm constants for $\mathrm{Cu}$ (II) adsorption onto EA}

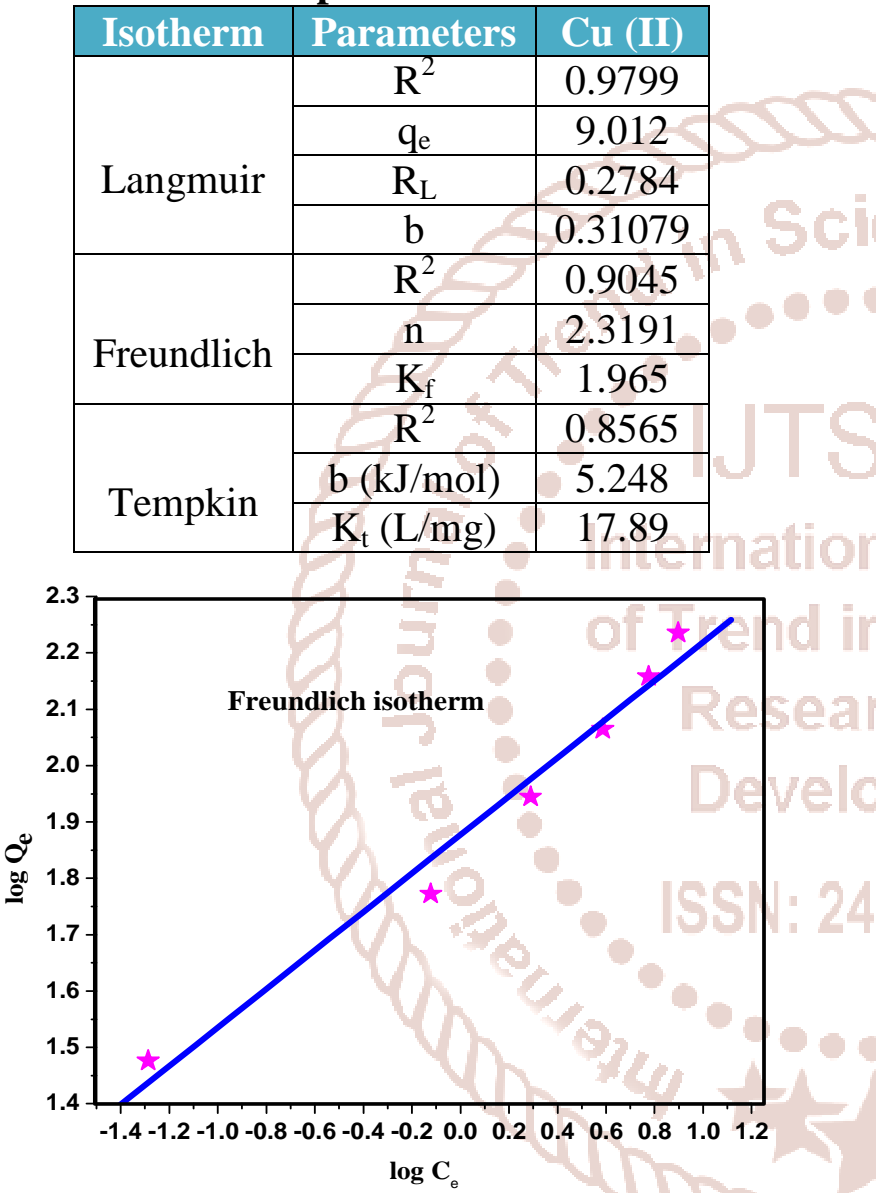

Fig.8. Freundlich isotherm

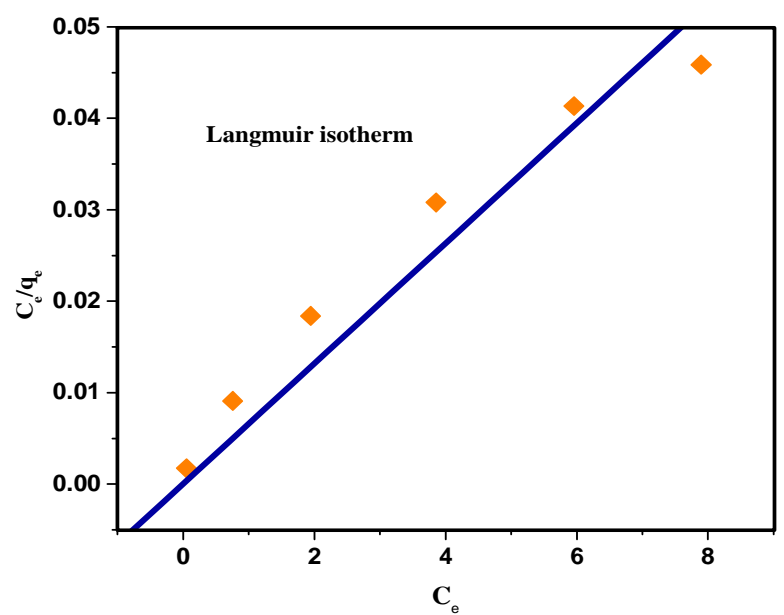

Fig.9. Langmuir isotherm

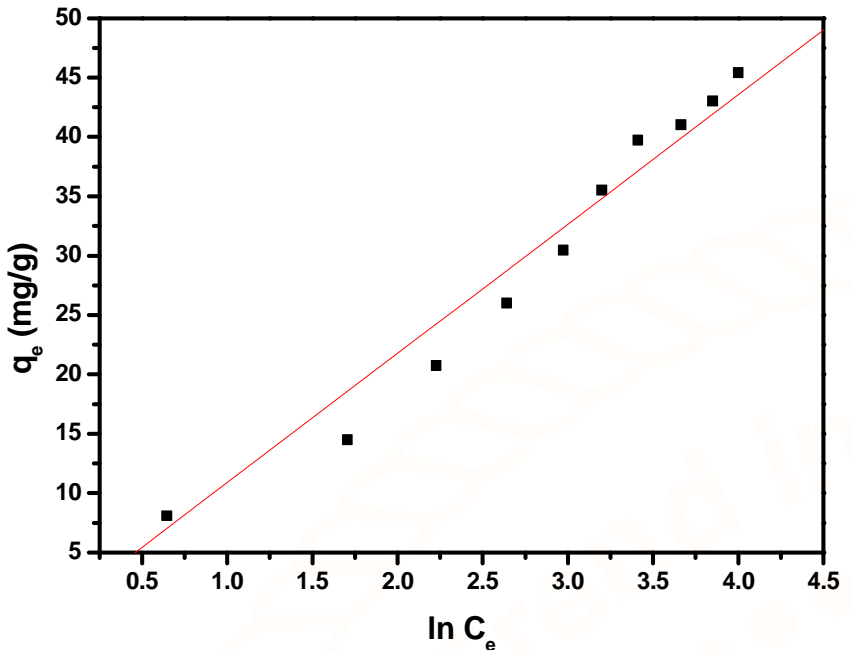

Fig.10. Temkin isotherm

\subsection{Adsorption kinetics}

Several models can be used to express the mechanism of $\mathrm{Cu}^{2+}$ adsorption onto an EA bio sorbent. The kinetic models of adsorption were determined with two most commonly used and known rate equations: pseudo first order (the most reliable kinetics equation suitable only for the rapid initial phase Equation 6) and pseudo second order (for predicting the kinetics behavior of chemical sorption as a rate controlling step Equation 7) models are expressed as

$$
\begin{aligned}
& \log \left(\mathrm{q}_{\mathrm{e}}-\mathrm{q}_{\mathrm{t}}\right)=\log \mathrm{q}_{\mathrm{e}}-\frac{K_{1}}{2.303} \cdot t \\
& \frac{t}{q_{t}}=\frac{1}{K_{2} q_{e}^{2}}+\frac{1}{q_{t}} \cdot \mathrm{t}
\end{aligned}
$$

Where $\mathrm{q}_{\mathrm{e}}$ and $\mathrm{q}_{\mathrm{t}}$ are the amounts of metals adsorbed $\left(\mathrm{mg} \mathrm{g}^{-1}\right)$ at equilibrium and at time $\mathrm{t}(\mathrm{min})$ respectively. $\mathrm{K}_{1}\left(\mathrm{~min}^{-1}\right)$ is the rate constant of pseudofirst order. The linear relation among the value of $\log$ $\left(\mathrm{q}_{\mathrm{e}}-\mathrm{q}_{\mathrm{t}}\right.$ ) versus $\mathrm{t}$ (Fig. 11) reveals the applicability of this model. $\mathrm{K}_{2}$ and the equilibrium adsorption amount $\left(\mathrm{q}_{\mathrm{e}}\right)$ were measured from the slope and intercept of the plot of $\mathrm{q}_{\mathrm{t}}$ versus $\mathrm{t}$ (Fig. 12). Where $\mathrm{k}_{2}(\mathrm{~g} /(\mathrm{mg} \mathrm{min})$ )is the rate constant of pseudo-second order kinetic model. $\mathrm{h}$ is known as initial sorption constant (Table $6)$. The high values of $\mathrm{R}^{2}$ were recorded for the Pseudo second order compared to pseudo-first order model. This indicates that the adsorption kinetic was better represented by the pseudo-second order model for all metal ions. Therefore, the overall rate of the metal ions adsorption process appears to be controlled by the chemical process via ion exchange and/or complex process [19-21]. 
International Journal of Trend in Scientific Research and Development (IJTSRD) ISSN: 2456-6470

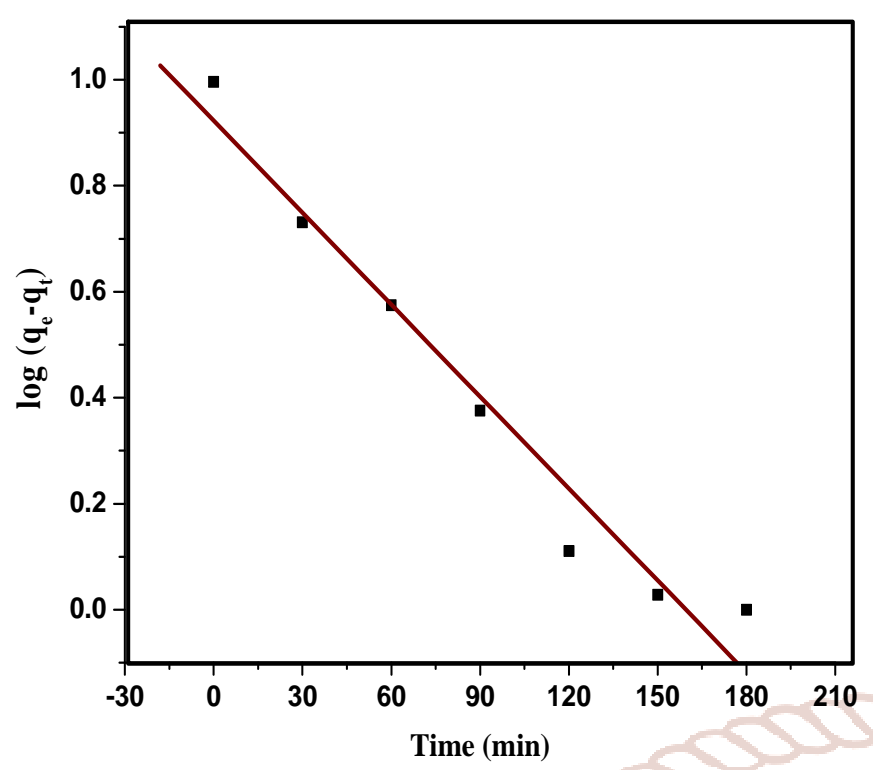

Fig.11. Pseudo first order kinetics

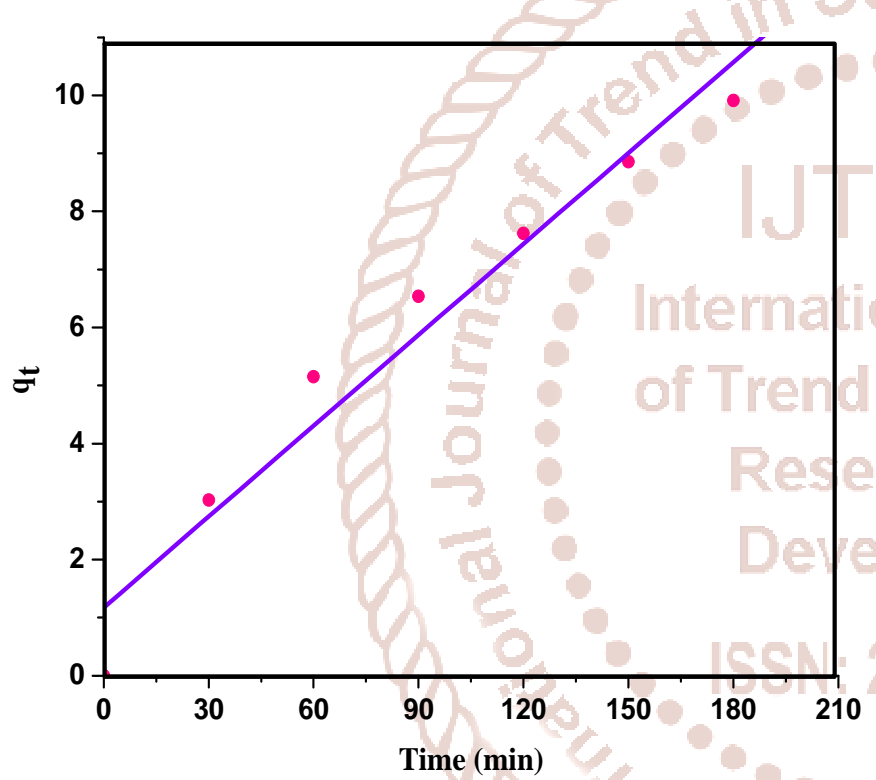

Fig.12. Pseudo second order kinetics

Table-6: Different kinetic model parameters

\begin{tabular}{|c|c|c|}
\hline Models & Parameters & $\mathrm{Cu}(\mathrm{II})$ \\
\hline & $\mathrm{q}_{\mathrm{e}}, \exp (\mathrm{mg} / \mathrm{g})$ & 9.2 \\
\hline \multirow{3}{*}{ Pseudo-first order model } & $\mathrm{R}^{2}$ & 0.85 \\
& $\mathrm{k}_{1}\left(\mathrm{~min}^{-1}\right)$ & 0.0207 \\
& $\mathrm{q}_{\mathrm{e}, \mathrm{cal}}(\mathrm{mg} / \mathrm{g})$ & 0.657 \\
\hline & $\mathrm{R}^{2}$ & 0.984 \\
Pseudo-second order & $\mathrm{h}(\mathrm{mg} / \mathrm{g} \mathrm{min})$ & 0.1034 \\
model & $\mathrm{k}_{2}(\mathrm{~g} / \mathrm{mg} \mathrm{min})$ & 0.0834 \\
& $\mathrm{q}_{\mathrm{e}, \mathrm{cal}}(\mathrm{mg} / \mathrm{g})$ & 9.35 \\
\hline
\end{tabular}

\section{CONCLUSION}

The potential of natural Eclipta Alba as a low cost material for the removal of copper from synthetic metal solutions was studied and the bio sorbent were successfully characterized using SEM and BET technique. A number of experiments were performed in order to determine this potential; equilibrium adsorption capacity, $\%$ removal of metal ions. The maximum adsorption capacities observed for $10 \mathrm{mg} / \mathrm{L}$ of $\mathrm{Cu}$ (II). A maximum of $92 \%$ metal ion removal was observed for copper. Various parameters like $\mathrm{pH}$, initial ion concentration, adsorbent dosage, and contact time were studied successfully. The maximum removal of metal ions at $10 \mathrm{mg} / \mathrm{L}$ of $\mathrm{Cu}$ (II) with 100 $\mathrm{mg} / \mathrm{L}$ of adsorbent dosage. The study indicates that the Eclipta Alba is a good candidate as a low cost adsorbent to be used for the removal of heavy metals from wastewater.

\section{ACKNOWLEDGEMENT}

The authors are thankful to Management of Cardamom Planters' Association CollegeBodinayakanur for having given facilities to carry out this research work.

\section{REFERENCE}

1. Aksu Z., İşoğlu I. A., Process Biochem. 40 (2005) 3031 .

2. Omgbu J A and Kokogbo M A, Environ Int., 19 (19993) 611.

3. Yusuf A A, Arowolo T A and Bombose O, Food Chem Toxicol., 41(3) (2003) 375.

4. Ajibola V O and Ozigis I, J Chem Soc Nigeria, 30 (2005) 62.

5. - Inglezakis V J, Loizidou M D and Grigoropoulou H P, J Colloid Interface Sci., 49 (2003) 261.

6. Horsfall M. J., Abia A. A., Spiff A. I, Bioressource and Technology, 97 (2) (2006) 283.

7. Anagho Gabche S., Ketcha Mbadcam J., Kammegne A. M., Ndi Nsami J., Nche NdiforAngwafor G., and Tchuifon Tchuifon D.R., Dee Chemica Sinica.4 (3) ) (2013) 58.

8. T. S. Anirudhan and P. G. Radhakrishnan, J. Chem. Therm., 40 (2008) 702.

9. H. Duygu, H. Kumbur, B. Saha and J. Hans Van Leeuwen, Biores. Tech., 99 (2008) 4943.

10. Xiaomin Li, Yanru Tang, Xiuju Cao, Dandan Lu, fang Luo, Wenjing Shao, Colloids and Surfaces, 317 (2008) 512.

11. N. Yeddou Mezenner, A. Bensmaili, Kinetics and thermodynamic study of phosphate adsorption on iron hydroxide-eggshell waste, 
Chemical Engineering Journal, Volume 147, 17. Naghizadeh A., Journal of Water Supply:

Issues 2-3 (2009) 87.

12. Haq Nawaz, Rabia Khalid, and Muhammad Asif., Journal of Hazardous materials., 148 (2009) 434.

13. Mezenner, N. Y., and Bensmaili, A. Chem Eng J. 147 ( 2-3) (2009) 87.

14. AsmaHanif, Haq Nawaz Bhatti, and Muhammad AsifHanif., Journal of Bio resource Technology, 35 (2009) 1427.

15. Olga Freitas, Cristina Delerue-Matos, Rui Boaventura., Journal of Physical Chemistry, 30(2) (2011) 177.
Research and Technology-AQUA, 64(1) (2015) 64.

18. Naghizadeh A., Shahabi H., Ghasemi F., Zarei A., Journal of Water and Health, 14(6) (2016) 889.

19. Moussavi G., Mahmoudi M., Chemical Engineering Journal, 152(1) 2009) 1.

20. Jamshidi B., Ehrampoush M. H., Dehvari M., Journal of Environmental Treatment Techniques, 1(3) (2013) 151.

21. Kavitha B, Sarala Thambavani D, Chem Sci Rev Lett 3 (12) (2014) 847.

16. Z Yao, J Qi, and L Wang., Journal of Applied surface science, 174 (2010) 137. 